\title{
Immunisation of adults during an outbreak of diphtheria
}

\author{
S R PALMER, A H BALFOUR, A E JEPHCOTT
}

\begin{abstract}
In an outbreak of infection due to Corynebacterium diphtheriae in a hospital for mentally subnormal adults sera from 211 members of staff were screened for diphtheria antitoxin titres. Of these, $79(37 \%)$ required immunisation, and a low dose preparation (1 Lf U of diphtheria and 10 LfU tetanus toxoids) was offered. Of the 64 subjects who accepted a single immunisation and were subsequently retested, seroconversion to diphtheria toxoid occurred in $45(70 \%)$, the rate being highest in younger adults. Seroconversion to tetanus toxoid occurred in $59 \%$ of subjects. Local reactions to the single dose were reported by $29(43 \%)$ subjects, and nine $(13 \%)$ experienced moderately severe local reactions and systemic symptoms.

We conclude that adults should not be vaccinated without previous screening for susceptibility to diphtheria; that neither previous immunisation nor age is reliable in predicting the need for vaccination; and that though a single booster dose of diphtheria toxoid is probably effective in adults under 45 , two doses should be given to those in the older age group.
\end{abstract}

\section{Introduction}

One difficult and still unresolved ${ }^{12}$ aspect of controlling outbreaks of toxigenic Corynebacterium diphtheriae infection is the immunisation of adults. Severe reactions related to the dose of toxoid and the immune state of recipients have occurred, and even with low dose vaccines side effects are not uncommon. ${ }^{3}$ For these reasons adults are usually tested by the Schick test and offered vaccine only if they have a positive reaction. With the Schick test, however, difficulties may be met in obtaining the reagents and in carrying out the test when large numbers of adults have been exposed to infection and need to be protected quickly. For this reason the success of a low dose (1.5 LfU) diphtheria toxoid vaccine for use in adults who have not been screened by the Schick test is a welcome development. ${ }^{4}$ Experience in the United Kingdom with low dose vaccines for adults

Communicable Disease Surveillance Centre, London NW9 5EQ $S$ R PALMER, MA, MFCM, senior registrar in community medicine

Public Health Laboratory, Leeds

A H BALFOUR, PHD, MIBIOL, senior microbiologist

Public Health Laboratory, Bristol

A E JEPHCOTT, MD, FRCPATH, director (which are presently available only as combined diphtheria and $\stackrel{\omega}{\circ}$ tetanus vaccines) seems to be very limited, as does the use of the $\frac{5}{3}$ diphtheria antitoxin assay instead of the Schick test.

We have assessed the effect of a vaccine (Anatoxal $\mathrm{Di} \mathrm{Te}_{\infty}^{\infty}$ Berna, produced by the Swiss Serum Institute, Berne) containing $\sigma^{\circ}$ $1 \mathrm{LfU}$ of diphtheria and $10 \mathrm{LfU}$ of tetanus formol toxoids per $\mathscr{O}^{-}$ $0.5 \mathrm{ml}$ in an outbreak at a hospital for mentally subnormal adults by measuring serum antitoxin concentrations.

\section{Subjects and methods}

Over 200 members of staff were possibly exposed to $C$ diphtheriae $\stackrel{\mathbb{D}}{\mathrm{O}}$ infection during the outbreak. As Schick testing was not considered practicable serum antitoxin concentrations were measured in blood samples from all the staff.

Sera were examined for diphtheria antitoxin by a neutralisation assay using HeLa cells ${ }^{5}$ and for tetanus antitoxin by an enzyme linked. immunosorbent assay technique. ${ }^{6}$ Staff with titres of diphtheria antitoxin of $<0.01$ units $/ \mathrm{ml}$ were offered single $0.5 \mathrm{ml}$ doses of vaccine, which were given on 30 December 1981 and 6 January 1982. Further blood samples were collected from immunised staff between 28 January and 10 February 1982 and questionnaires recording $\stackrel{\circ}{D}$ possible adverse reactions completed. Subjects whose diphtheria antitoxin concentrations remained at $<0.01$ units $/ \mathrm{ml}$ and who did $\bar{O}$ not report adverse reactions were offered a second dose.

\section{Results}

DIPHTHERIA ANTITOXIN

Sera from 211 subjects were examined; of the 86 subjects with titres $<0.01$ units/ml, $79(37 \%)$ were offered immunisation against $ᄋ$ diphtheria because of continued exposure. Seventy two subjects accepted vaccination and 64 agreed to be retested; of these, 19 hado diphtheria antitoxin titres $<0.01$ units $/ \mathrm{ml}$ four to seven weeks after vaccination, of whom nine accepted revaccination. The proportion of men and women with diphtheria antitoxin titres of $<0.01$ units $/ \mathrm{ml} D$ increased with age (table I); half of those over 45 had titres $<0.01$ 을. units $/ \mathrm{ml}$.

A history of diphtheria immunisation in childhood was given by 77 subjects. Proportionately fewer subjects who had been immunised $\omega$ had antitoxin titres of $<0.01 \mathrm{units} / \mathrm{ml}$ (table II), but the association with antitoxin titres was not statistically significant.

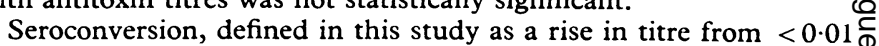
units $/ \mathrm{ml}$ to $>0.01 \mathrm{units} / \mathrm{ml}$ after one dose of $1 \mathrm{LfU}$ diphtheria $\stackrel{\mathscr{P}}{\rightarrow}$ toxoid, occurred in 45 of 64 subjects who were retested. The pro- $\square$ portions of those born after 1944 and between 1935 and 1944 whoo seroconverted were $8 / 9(89 \%)$ and $17 / 20(85 \%)$ respectively, but in $\overrightarrow{\mathbb{P}}$ those born before 1935 the rate was significantly lower at 20/35 (57\%) $(p<0.05)$. Nineteen of the $21(86 \%)$ people who had been immunised in childhood seroconverted compared with 10 of the $22(45 \%)$ noto immunised and 16 of the $20(80 \%)$ who did not know. All those subjects born after 1934 who said they had been immunised ino childhood seroconverted after single doses but only four of the seven born after 1935 who said they had been immunised previously did so. 


\section{TETANUS ANTITOXIN}

Sera of 62 subjects who were offered immunisation were also tested for tetanus antitoxin. Of these, $17(27 \%)$ had titres $<0.01$ units/ml before immunisation, and seven of the $17(41 \%)$ failed to seroconvert after single doses of vaccine containing $10 \mathrm{LfU}$ tetanus toxoid.

\section{ADVERSE REACTIONS}

Of the 68 subjects given first doses of vaccine and who completed questionnaires, only $25(37 \%)$ did not report reactions. Twenty three reported soreness, 15 pain, redness, and swelling at the injection site, and four tenderness in the axilla as well as pain at the injection site; 12 complained of headache, two of swollen puffy eyes for up to four days, three of tiredness, one each of paraesthesiae in the arm, shivering, and dizziness, and two of nausea. The severity of the reactions was assessed by recording the duration of symptoms, time off work, and disruption of normal activities including sleep. Of the 38 with soreness concentrations of $<0.01$ units $/ \mathrm{ml}$. Thus even a reported history 黑 of childhood immunisation was not a reliable prediction of protective antibody concentrations in adults.

The dose of toxoid conventionally given to children is $25 \mathrm{LfU}$; after a dose of only $1 \mathrm{LfU}$ seroconversion occurred in $70 \%$ of the 64 subjects immunised and retested four to seven weeks later. This proportion is slightly smaller than the seroconversion rate found by Sheffield et $a l^{4}$ using a $1.5 \mathrm{LfU}$ preparation but is similar to that in Australian medical students given a single dose of $5 \mathrm{LfU} .^{7}$ Of the younger members of staff, whose ages were nearer to those of the medical students, over $85 \%$ seroconverted. Despite their low initial diphtheria antitoxin titres these subjects had very probably been previously exposed to the antigen. In this age group a reported history of immunisation in childhood could be used to predict seroconversion whereas in older subjects (born before 1935) it was probably inaccurate and bore little relation to seroconversion.

Despite using a low dose vaccine reactions were reported in

TABLE I-Proportion of men and women with diphtheria antitoxin titres $<0.01$ units/ml by age

\begin{tabular}{|c|c|c|c|c|c|c|c|}
\hline & \multicolumn{7}{|c|}{ No of subjects in age (years) groups: } \\
\hline & Unknown & $<25$ & $25-34$ & $35-44$ & $45-54$ & $\geqslant 55$ & Total \\
\hline $\begin{array}{l}\text { Men } \\
\text { Women }\end{array}$ & $\begin{array}{l}4 / 12 \\
5 / 11\end{array}$ & $\begin{array}{l}3 / 8 \\
0 / 7\end{array}$ & $\begin{array}{l}1 / 15 \\
3 / 9\end{array}$ & $\begin{array}{c}2 / 9 \\
17 / 37\end{array}$ & $\begin{array}{r}7 / 13 \\
22 / 45\end{array}$ & $\begin{array}{l}10 / 19 \\
12 / 26\end{array}$ & $\begin{array}{l}27 / 76 \\
59 / 135\end{array}$ \\
\hline Total (" & $9 / 23(39)$ & $3 / 15(20)$ & $4 / 24(17)$ & $19 / 46(41)$ & $29 / 58(50)$ & $22 / 45(49)$ & $86 / 211(41)$ \\
\hline
\end{tabular}

TABLE $11-D i p h t h e r i a$ antitoxin titres in 211 adults

\begin{tabular}{|c|c|c|c|c|c|c|c|c|}
\hline \multirow{2}{*}{$\begin{array}{l}\text { History of } \\
\text { immunisation }\end{array}$} & \multicolumn{8}{|c|}{ No of subjects with following titres: } \\
\hline & 0.01 & 0.0195 & 0.039 & 0.078 & $0 \cdot 156$ & 0.312 & $>0.32$ & Total \\
\hline $\begin{array}{l}\text { Yes } \\
\text { No/not known }\end{array}$ & $\begin{array}{l}28 \\
58\end{array}$ & $\begin{array}{l}10 \\
11\end{array}$ & $\begin{array}{r}99 \\
23\end{array}$ & $\begin{array}{l}13 \\
12\end{array}$ & $\begin{array}{r}8 \\
11\end{array}$ & $\begin{array}{l}5 \\
8\end{array}$ & $\begin{array}{r}4 \\
11\end{array}$ & $\begin{array}{r}77 \\
134\end{array}$ \\
\hline Total $\left({ }^{\circ}{ }_{0}\right)$ & $86(41)$ & $21(10)$ & $32(15)$ & $25(12)$ & $19(9)$ & $13(6)$ & $15(7)$ & 211 \\
\hline
\end{tabular}

of the arm, it had lasted for two days or more in 24 and for seven days in two. Only one subject had stayed away from work (for three days) as a result of the injection; sleep had been disrupted in seven and normal activities in two. In our view nine subjects had moderately severe reactions with general as well as local symptoms. In the 64 subjects retested after immunisation reported reactions were significantly associated with diphtheria antitoxin seroconversion; 11 of 22 $(50 \%)$ with no reactions seroconverted compared with 34 of $42(81 \%)$ with reactions $(p<0 \cdot 01)$.

Adverse reactions to immunisation were not significantly associated with high tetanus toxoid titres before immunisation. Of the 19 subjects who did not seroconvert to the diphtheria toxoid, eight had adverse reactions and of these, five had tetanus antitoxin titres $>0.01$ units $/ \mathrm{ml}$ before immunisation, which is similar to the proportion who did not report adverse reactions (13/22).

\section{Discussion}

Our finding that $41 \%$ of 211 subjects had antitoxin titres $<0.01$ units $/ \mathrm{ml}$ and were therefore possibly susceptible to infection is similar to that in a group of 60 medical students ${ }^{4}$ and emphasises the need to protect adult contacts in an outbreak of toxigenic $C$ diphtheriae infection.

In our study immune state correlated poorly with age and history of immunisation in childhood. Those born after mass immunisation was introduced in the United Kingdom were more likely to be immune, but even so $18 \%$ of those under 35 required immunisation. Moreover, $36 \%$ of those claiming to have been immunised in childhood had diphtheria antitoxin
$71 \%$ of the vaccinated subjects. In $38 \%$ these reactions were pronounced local reactions, which included pain in the axilla and redness, swelling, and pain at the injection site. Only 13 $(15 \%)$ such reactions were reported in 89 medical students. ${ }^{4}$ Only nine $(13 \%)$ of the staff in our study, however, had moderately severe reactions with systemic symptoms. Some of these reactions may have been due to the tetanus toxoid component, as suggested by Collier in $1979,{ }^{8}$ but only diphtheria antitoxin titres were significantly associated with reported reactions.

From our experience of control measures in a diphtheria $N$ outbreak among adults we recommend that: $(a)$ neither a history of immunisation nor the age of an adult should be relied on to predict need of immunisation (diphtheria antitoxin titres $<0.01$ units $/ \mathrm{ml}$ ); $(b)$ that because of the relatively high rate of (mainly mild) reactions to single doses of $1 \mathrm{LfU}$ diphtheria and $10 \mathrm{LfU}$ tetanus toxoid adults should not be vaccinated without previous screening for susceptibility; and (c) that though a single booster dose of $1 \mathrm{LfU}$ may be effective in adults under 45 years older $\mathbb{\infty}$ adults should be given two doses, since in about $40 \%$ of these adults diphtheria antitoxin titres may remain below 0.01 units $/ \mathrm{ml}$ after a single dose.

We thank Dr J Abbott, Public Health Laboratory Service, Manchester, for helpful advice at all stages of this work, and Dr F Sheffield of the National Institute for Biological Standards and Control for commenting on this manuscript. This work was supported in part by a Medical Research Council equipment grant (No G 81109925B) to AHB. 


\section{References}

1 Ellison S. Immunisation of adults against diphtheria. Br Med f 1978;ii:962.

2 Abbott JD, Ironside AG, Sheffield FW. Immunisation of adults against diphtheria. Br Med f 1978;ii:1371.

${ }^{3}$ Middaugh JP. Side effects of diphtheria-tetanus toxoid in adults. $A m \mathcal{H}$ Public Health 1979;69:246-9.

4 Sheffield FW, Ironside AG, Abbott JD. Immunisation of adults against diphtheria. Br Med f 1978;ii:249-50.

${ }^{5}$ Miyamura K, Nishi S, Ito A, Murata R, Kona R. Microcell culture method for determination of diphtheria toxin and antitoxin titres using VERO cells. Studies on factors affecting the toxin and antitoxin titration. f Biol Stand 1974;2:189-201.
${ }^{6}$ Melville-Smith ME, Seagroatt VA, Watkins JT. Comparison of enzymelinked immunosorbent assay (ELISA) with the toxin neutralization tes in mice, as described for the estimation of tetanus antitoxin in human sera. $\mathcal{F}$ Biol Stand (in press).

' Feery BJ, Benenson AS, Forsyth JRL, Manser MA, Minty DW. Diphtheria immunization in adolescents and adults with reduced doses of adsorbed diphtheria toxoid. Med f Aust 1981;1:128-30.

${ }^{8}$ Collier LH, Polakoff S, Mortimer J. Reactions and antibody responses to reinforcing doses of adsorbed and plain tetanus vaccines. Lancet 1979 ; 1364-8.

(Accepted 30 December 1982)

\title{
Lesson of the Week
}

\section{Recurrent meningitis due to congenital malformation of the inner ear}

\author{
M W M BRIDGER, P D PHELPS
}

Congenital malformations of the inner ear may be associated with deafness, a cerebrospinal fluid fistula, and recurrent attacks of meningitis. ${ }^{1}$ When there is a leak of cerebrospinal fluid and the tympanic membrane is intact the fluid enters the nasopharynx through the eustachian tube, where it may be very difficult to detect. ${ }^{2}$ We report on a case of recurrent meningitis that occurred in a child with congenital deafness. The site of cerebrospinal fluid leakage was not detectable clinically but was accurately predicted by complex motion tomography and confirmed surgically.

\section{Case report}

A 5 year old boy was admitted to the Middlesex Hospital on 19 February 1981, having suffered four attacks of pneumococcal meningitis in the previous seven months-in July 1980, September 1980, January 1981, and February 1981. After the second attack he was admitted to a neurosurgical department for investigation. No cause for the attacks was found, and he was discharged without treatment.

The child had had a full term normal delivery. He sat at 1 year and walked at 18 months. A severe bilateral sensorineural deafness and right VI nerve palsy were diagnosed during the first year of life. He had been fitted with bilateral body worn hearing aids and attended a special school for the deaf but could not talk. There was no family history of deafness, and one other child is alive and well. The clinical examination was normal except for deafness, a right VI nerve palsy, and the absence of speech. In particular, there was no evidence of a leak of cerebrospinal fluid from the ears or nose and throat, and none had been seen either at home or on previous hospital admissions.

Middlesex Hospital, London W1N 8AA

$M$ W M BRIDGER, FRCs, senior registrar in otolaryngology

Royal National Throat, Nose, and Ear Hospital, London WC1X 8DA P D PHELPS, FRCS, consultant radiologist
Recurrent attacks of meningitis in a deaf child may indicate a congenital malformation of the inner ear associated with a cerebrospinal fluid fistula

Preliminary investigations including full blood count, concentrations of urea and electrolytes, nose and throat swabs, immunoglobulin concentrations, skull radiographs, and computed tomography of the head and floor of the anterior cranial fossa gave normal results. Polytomography of the inner ears, however, showed dilated labyrinths on each side with an evagination from the vestibule replacing the lateral semicircular canal. The cochleae were also dilated, particularly on the right, where there was an incompletely formed central bony spiral.

Because of the labyrinthine dysplasia it was thought that there was a fistulous communication between the subarachnoid space, abnormal labyrinth, and middle ear cavity, probably through the oval window. The right abducens palsy and more severe anatomical deformities on the right suggested that surgical exploration of this side should be done.

Tympanotomy showed that the mucosa surrounding the oval window was ballooned and that a small amount of clear fluid had collected just anterior to the stapes footplate. Clearly, a continuous leak of cerebrospinal fluid was escaping from the margin of the oval window and collecting in the middle ear through a small rupture in the ballooned mucosa. The stapes bone was removed and this resulted in a torrential flow of clear fluid under pressure. It was thus impossible to establish the site of communication with the subarachnoid space. The vestibule was packed firmly with a large quantity of temporalis muscle and this was covered with a sheet of temporalis fascia.

After the operation phenoxymethylpenicillin and chloramphenicol elixir were given for 10 days, and then all medication was stopped. There was no postoperative vertigo or nystagmus, which confirmed the preoperative impression of a non-function- 